\title{
Concerns of patients with allergic rhinitis: the Allergic Rhinitis Care Programme in South Africa
}

\author{
*Robin John Green ${ }^{\mathrm{a}}$, Gloria Davis ${ }^{\mathrm{b}}$, David Price \\ a Department of Paediatrics, University of Pretoria, South Africa \\ b South African Allergic Rhinitis Working Group \\ c Department of General Practice and Primary Care, University of Aberdeen, Scotland, UK
}

Received 12th December 2006; accepted 11th June 2007

\begin{abstract}
Background: The major reason for treating chronic rhinitis is to improve quality of life. Although primary symptoms cause morbidity in their own right, these symptoms are significantly aggravated by the impact of cognitive dysfunction and quality of life.

Objective: The Allergic Rhinitis Care Programme was initiated by the South African Allergic Rhinitis Working Group. An important task of this programme was to document health-related quality of life impairment amongst allergic rhinitis patients in South Africa.

Methods: A questionnaire, appropriate to South Africa, was distributed to patients. The questionnaire inquired about symptoms, quality of life, complications, trigger factors, associated allergic conditions, medication preference, medication adherence and concerns about the condition.

Results: 1181 people completed the questionnaire and returned the survey. Nasal congestion was identified as a common and frequent problem, while seasonality of symptoms was uncommon. Symptoms affected sleep in $76.6 \%$ of sufferers, and in at least a third this was every night. Over 1000 respondents felt miserable due to allergic rhinitis (85.2\%). $63.1 \%$ indicated that they always followed instructions for taking rhinitis medication. A variety of perceived concerns around having and being treated for allergic rhinitis were identified, suggesting multiple reasons for non-adherence.

Conclusions: We report symptom frequency and quality of life impairment for respondents who identify themselves as having allergic rhinitis. Since allergic rhinitis is, in the main, a doctor-diagnosed condition, this would suggest a significant problem with inappropriate, insufficient or incorrect therapy.

C 2007 General Practice Airways Group. All rights reserved.

RJ Green, et al. Prim Care Resp J 2007; 16(5): 299-303.

doi:10.3132/pcrj.2007.00062
\end{abstract}

Keyw ords allergic rhinitis, quality of life, nasal congestion, non-adherence

\section{Introduction}

Rhinitis is not a life-threatening condition, and although this has perhaps trivialised its status, it places greater emphasis on patient well-being as an outcome measure. In fact, the major reason for treating chronic rhinitis is to improve quality of life. ${ }^{1}$ As a disease, it has major ramifications in terms of associated morbidity and cost. Although primary symptoms (rhinorrhoea, nasal congestion, sneezing and itch) cause morbidity in their own right, these symptoms are significantly aggravated by associated problems of ear and sinus disease, as well as the impact of cognitive dysfunction and quality of life..$^{2-6}$
The South African Allergic Rhinitis Working Group (SAARWG) was convened by interested allergists, pediatricians, Ear Nose and Throat (ENT) Surgeons, and General Practitioners (GPs). In 1996, the group met to discuss and publish guidelines for the diagnosis and management of allergic rhinitis in South Africa. ${ }^{7}$ International Guidelines ${ }^{8}$ had recently been published, but at this first meeting, and subsequently, a need was expressed to document the problems and concerns of patients with allergic rhinitis in South Africa. The Allergic Rhinitis Care Programme was born. An important task of this programme was to document

\footnotetext{
* Corresponding author: P.O. Box 1150, Randpark Ridge, 2156, South Africa.

Tel: +2711 793-3487 Fax: +2711 792-1360 E-mail: robgreen@global.co.za
} 
Table 1. Symptoms of allergic rhinitis $(n=1181)(\%)$.

\begin{tabular}{|c|c|c|c|c|c|}
\hline Symptom & $\begin{array}{c}\text { More than } \\
\text { once a week }\end{array}$ & $\begin{array}{c}\text { More than } \\
\text { once a month }\end{array}$ & Occasionally & $\begin{array}{c}\text { Seasonally } \\
\text { (eg. in spring) }\end{array}$ & Never \\
\hline Nasal congestion & $612(51.8)$ & $170(14.4)$ & $155(13.1)$ & $129(10.9)$ & $14(1.2)$ \\
\hline Sneezing & $558(47.3)$ & $170(14.4)$ & $199(16.9)$ & $152(12.9)$ & $57(4.8)$ \\
\hline Itching in the nose & $458(38.8)$ & $185(15.7)$ & $222(18.8)$ & $135(11.4)$ & $57(4.8)$ \\
\hline
\end{tabular}

impairment in health-related quality of life amongst allergic rhinitis patients in South Africa. Subsequent to this study the SAARWG has prioritised patient education as a critical factor in the success of managing allergic rhinitis.

This study was deemed necessary to document the effects of diagnosis and pharmacological treatment on patient wellbeing and resolution of symptoms in patients with allergic rhinitis. The impact of these two factors alone requires documentation in devising patient education strategies. In addition, the concerns of patients with persistent allergic rhinitis needed quantification.

\section{Methods}

The members of the South African Allergic Rhinitis Working Group (Allergists, Paediatricians, Otorhinolaryngologists and GPs with an interest in allergic rhinitis) were asked to submit questions, based on experience and evidence, that they felt would best uncover the concerns of patients with regard to allergic rhinitis. A 20-question questionnaire, appropriate to South Africa, was compiled. These questions were tested for their ability to demonstrate reliability in a workshop of 50 volunteers with allergic rhinitis accompanied by two expert clinicians. The questionnaire was reduced to 11 questions in this way (see Appendix 1 at www.thepcrj.org). The pilot study revealed that the language was understandable by all patients (including those with limited formal education, and patients from different racial groups) and the question results correlated well with objective observer assessment of rhinitis control. The questionnaire inquired about symptoms, quality of life, complications, trigger factors, associated allergic conditions, medication preference, medication adherence and concerns about the condition. Respondents were asked about perceived concerns around having, and being treated for, allergic rhinitis.

\section{Patient recruitment}

General Practitioners (GPS), ENT surgeons and Pharmacists (in South Africa) were randomly identified from the Medical Association database. These individuals were approached to recruit patients. Twenty of each group were identified in each of five major centres (Johannesburg, Pretoria, Durban, Cape
Table 2. Do allergic rhinitis symptoms affect the quality of your sleep? $(n=1181)(\%)$.
Affect sleep quality
904 (76.6)
- Every night
$439(37.2)$
- Less than once a week
$348(29.5)$
- Less than once a month
$177(15.0)$

Town and Bloemfontein). They invited all their patients known to have allergic rhinitis to complete the questionnaire. All patients had to have a clinical history of chronic nasal symptoms (nasal blockage, rhinorrhoea, sneezing or itch) together with a positive allergy test (skin prick test or RAST) to common aero-allergens. Other causes of chronic rhinitis had to be excluded in the judgement of the clinician. The questionnaire was titled 'Questionnaire for allergic rhinitis sufferers'. The survey was, however, targeted to selected patients and not a random population sample. All respondents completed written informed consent, and ethics approval (from the Medicines Control Council South Africa) was obtained for the study.

In an attempt to identify the impact of allergic rhinitis on quality of life, two questions were asked; 'Do these symptoms affect the quality of your sleep?'; and 'Does rhinitis make you feel miserable?' In an attempt to document the extent of non-adherence to chronic medication, a number of questions were posed - for example; 'Do you always follow instructions for taking rhinitis medication?'

\section{Results}

One thousand two hundred patients were approached to participate between October 2002 and September 2003. All patients were employed and had medical insurance. 1181 patients (521 male) ranging in age from $5-67$ years (mean 32 years, SD 15.12) completed the questionnaire and returned the survey. Parents of children were asked to complete the questionnaire on behalf of children unable to do so. The number of 'proxy' responses from children was less 
Table 3. Triggering factors $(n=1181)(\%)$.

\begin{tabular}{|c|c|c|c|c|c|}
\hline Factor & Not at all & Very little & Moderately & Quite a lot & A great deal \\
\hline Changes in weather & $72(6.1)$ & $112(9.5)$ & $224(19.0)$ & $319(27.0)$ & $322(27.3)$ \\
\hline Pets & $212(18.0)$ & $198(16.8)$ & $205(17.4)$ & $166(14.1)$ & $176(14.9)$ \\
\hline Food & $373(31.6)$ & $198(16.8)$ & $191(16.2)$ & $82(6.9)$ & $71(6.0)$ \\
\hline Emotional upset & $370(31.3)$ & $179(15.2)$ & $179(15.2)$ & $112(9.5)$ & $81(6.9)$ \\
\hline
\end{tabular}

NB: Some responses missing hence totals not $100 \%$

than 20. This was a response rate of $98 \%$. One third (34\%) of questionnaires were returned from GPs, one third (31.5\%) from pharmacies, and one third (34.5\%) from ENT surgeons. There was no significant difference in response rate between these groups.

Table 1 documents the response of individuals to specific questions and their frequency. Nasal congestion is identified as a common and frequent problem, while seasonality of symptoms was uncommon.

Symptoms affected sleep in $76.6 \%$ of sufferers, and for at least a third this was every night (Table 2). Over one thousand respondents felt miserable due to allergic rhinitis (85.2\%).

Associated conditions of sinusitis, asthma and eczema were reported frequently. The description of headaches around the nose, cheeks and/or forehead was identified as 'sinus-related headaches' in $76.2 \%$ of patients at least occasionally. Three-hundred-and-six patients $(25.9 \%)$ had symptoms more than once a week, $226(19.1 \%)$ had symptoms more than once a month, and only 135 (11.4\%) never had sinus symptoms. In terms of symptoms and a possible previous doctor-diagnosis of asthma, $58.3 \%$ of respondents identified a history of asthma (coughing, wheezing and chest tightness), and $46.0 \%$ a past history of present or past eczema (itchy skin and rash).

Table 3 reflects the results of questions on triggering/exacerbating factors and their frequency. Pollen, a smokey atmosphere, air pollution and changes in weather were frequent exacerbating factors. Pet exposure was not considered a major factor.

Sixty-three percent indicated that they always followed instructions for taking medication. Reasons given for nonadherence are documented in Table 4. Table 5 attempts to document patient preference for medication.

Finally, the responses to questions about perceived

\section{Table 4. Reasons for non-adherence $(n=1181)(\%)$.}

Forget to take my medicines

$351(29.7)$

Worry about side effects

$551(46.7)$

Do not like the method

Take what I need

$90(7.6)$

$693(58.7)$

Taking medicine is admitting defeat

$104(8.8)$

Cannot afford medicine

$271(23.0)$

Stop taking medicine when better

$737(62.4)$

\section{Table 5. Medication preference $(n=1181)(\%)$.}

$\begin{array}{lc}\text { Route } & \\ \text { Nose spray } & 449(40.5) \\ \text { Tablets } & 614(55.4) \\ \text { Both } & 45(4.1)\end{array}$

\section{Table 6. Concerns about rhinitis $(n=1181)(\%)$}

$\begin{array}{ll}\text { It may last life-long } & 898(76.0) \\ \text { Effects of the medicine } & 686(58.1) \\ \text { Passing rhinitis on to children } & 491(41.6) \\ \text { Feeling self-conscious } & 602(51.0) \\ \text { Social activities restricted } & 627(53.1)\end{array}$

concerns around having, and being treated for, allergic rhinitis are documented in Table 6. Again, a variety of responses are noted.

\section{Discussion}

This study has a number of significant limitations. Firstly, the 
questionnaire has not been validated nor translated into multiple languages. The quality of life questionnaire developed by Juniper ${ }^{9}$ would be a useful follow-up tool. Secondly, the questionnaire is also not specific to a quality of life study, but is an attempt to document multiple concerns of South Africans with allergic rhinitis.

This study is part of an ongoing survey of health needs of South Africans with allergic diseases, since these conditions often are considered low priority when compared to more serious infectious diseases.

Allergic rhinitis in South Africa is a common problem and is most often a persistent disease. ${ }^{10-12}$ This is borne out by this study in which patients note seasonality of symptoms in only $10.9 \%-12.9 \%$ of cases. Persistent disease may contribute to symptom severity and quality of life impairment. The ISAAC Study conducted in 1998 revealed a prevalence of allergic rhinitis of $16 \%$ in Cape Town school children. ${ }^{12}$ This prevalence has increased in recent surveys. ${ }^{13}$

This study is important in its documentation of the problems that may be experienced by patients with allergic rhinitis. Almost half of the patients in South Africa have symptoms at least once a week, and over one third have sleep disruption every night due to allergic rhinitis. The persistence of allergic rhinitis in South Africa is due, at least in part, to the climate of the country. ${ }^{14}$ It is not surprising, therefore, that pollen is identified as a trigger factor in at least $70.4 \%$ of respondents. Using the two broad questions of sleep and 'feeling miserable' it appears that allergic rhinitis significantly affects quality of life. Despite the lack of specificity of these questions for this condition it should be remembered that these individuals identify these as problems as a consequence of their disease. This fact needs to be borne in mind by clinicians treating patients with allergic rhinitis. Bousquet et al reported that more than $80 \%$ of patients had impaired daily activities if they had moderate or severe allergic rhinitis, and even $40 \%$ of patients with mild disease report impairment. ${ }^{1}$

This study also documents the reasons for non-adherence to therapy and suggests that the phenomenon of nonadherence may, as with asthma, have a differential diagnosis. Not all patients fail to adhere to their therapy for a single reason and this must be borne in mind by clinicians treating such patients. This may provide education bodies with the tools to sort out this complex problem and permit the development of questionnaires that attempt to document non-adherence in a non-punitive manner and permit patients to indicate their concerns to busy doctors.

The survey also highlights the individual preference for route of therapy administration - and with the present availability of anti-inflammatory oral anti-histamines, careful patient selection and understanding of guidelines ${ }^{15}$ is mandatory. One size definitely does not fit all in terms of treating allergic rhinitis. Patients have many concerns about allergic rhinitis and clearly there is an opportunity now to address these issues - including the education of medical personnel, as well as education and support for patients. Ultimately, the doctor-patient interaction needs to be strengthened in order for the disease not to impact negatively on quality of life.

The finding that $63.1 \%$ of patients indicated that they always followed instructions regarding taking rhinitis medication is surprising. This may reflect the sampled group (those attending medical care). Not surprisingly, a range of responses is noted with regard to reasons for non-adherence. The denominator for non-adherence is left as the study total, since some individuals clearly indicated total adherence in one question but still answered specific questions on nonadherence.

What is particularly worrying about this survey is the symptom frequency and quality of life impairment reported by the respondents who identify themselves as having allergic rhinitis. Since allergic rhinitis is, in the main, a doctordiagnosed condition, this would suggest a significant problem with inappropriate, insufficient or incorrect therapy. Another possibility is, of course, non-adherence to therapy for a chronic condition. Either scenario suggests a role for better doctor-patient interaction regarding the therapy of this condition. Both patient and medical intervention, through education, are urgently required.

Furthermore, this study suggests that education on diagnosis and pharmacological treatment alone are insufficient to reduce the burden of allergic rhinitis. Treatment (in the broadest sense) should be instituted to reverse the effects of allergic rhinitis, and the selection of medication is of critical importance since non-adherence and poor patient understanding may detract from a successful outcome.

\section{Funding declaration}

GlaxoSmithKline (South Africa) provided a financial contribution towards the costs of this study.

\section{Conflict of interest declaration}

The authors declare that they have no conflict of interest in connection with this study.

\section{References}

1. Bousquet J, Neukirch F, Bousquet PJ, et al. Severity and impairment of allergic rhinitis in patients consulting in primary care. J Allergy Clin Immunol 2006;117: 158-62.

2. Marple BF, Fornadley JA, Patel AA, et al. Keys to successful management of patients with allergic rhinitis: Focus on patient confidence, compliance, and satisfaction. Otolaryngol Head Neck Surg 2007;136(6 Suppl):S107-24.

3. Pratt EL, Craig TJ. Assessing outcomes from the sleep disturbance associated with rhinitis. Curr Opin Allergy Clin Immunol 2007;7:249-56.

4. Braido F, Baiardini I, Brandi S, Porcu A, Canonica GW. Allergic rhinitis and asthma ad hoc survey: clinical and psychological perspectives. Clin Exp Allergy 2007;37:788-93. 
5. Stull DE, Roberts L, Frank L, Heithoff K. Relationship of nasal congestion with sleep, mood, and productivity. Curr Med Res Opin 2007;23:811-19.

6. Szeinbach SL, Seoane-Vazquez EC, Beyer A, Williams PB. The impact of allergic rhinitis on work productivity. Prim Care Resp J 2007;16:98-105. doi:10.3132/ pcrj.2007.00015

7. Luyt DK, Green RJ, Davis G et al. Allergic rhinitis in South Africa - diagnosis and management. S Afr Med J 1996;86(part 2):1313-28.

8. International Rhinitis Management Working Group. International Consensus report on the diagnosis and management of rhinitis. Allergy 1994;19:S1-\$32.

9. Juniper EF, Guyatt GH. Development and testing of a new measure of health status for clinical trials in rhinoconjunctivitis. Clin Exp Allergy 1991;2:77-83.

10. Cadman A. Incidence of atmospheric pollen in the Pretoria-Witwatersrand Vereeniging region during 1987/1988. S Afr Med J 1991;79:84-7.
11. Green RJ, Davis G. Allergy on the Highveld of South Africa. Allergy Clin Immunol Internat 2001;13:256-61.

12. ISAAC Steering Committee. Worldwide variation in prevalence of symptoms of asthma, allergic rhinitis and atopic eczema: ISAAC. Lancet 1998;351:122532.

13. Beasley R. The Global Burden of Asthma Report, Global Initiative for Asthma (GINA). Available from http://wwwginasthmaorg 2004

14. Potter PC, Mather S, Lockey P, Ainslie G, Cadman A. IgE specific immune responses to an African grass (Kikuyu, Pennisetum cladestinum). Clin Exp Allergy 1993;23:537-41.

15. GLORIA. Practical treatment guidelines for the management of allergic rhinitis and allergic conjunctivitis. EAACI brochure: 2000

\section{Available online at http://w ww.thepcrj.org}


Appendix 1. The Allergic Rhinitis Care Programme continued

\section{Do you suffer from either of the following?}

(Reply 'yes' even if you don't suffer from all these symptoms)

a. Asthma (symptoms include coughing, wheezing, chest tightness)

b. Eczema (symptoms include itchy skin and rash)

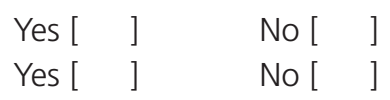

7. Which medicines are you currently taking for allergic rhinitis?

\begin{tabular}{|l|l|l|l|}
\hline $\begin{array}{l}\text { Name of medicine } \\
\text { (brand name on pack) }\end{array}$ & $\begin{array}{c}\text { Strength of medicine } \\
\text { (shown on pack, } \\
\text { e.g. } 20 \mathrm{mcg}, 100 \mathrm{mcg})\end{array}$ & $\begin{array}{c}\text { Number of puffs/tablets } \\
\text { per day } \\
\text { (e.g. 2,3) }\end{array}$ & $\begin{array}{c}\text { For how long have you } \\
\text { been using it? } \\
\text { (e.g. 6 months, } 1 \text { year) }\end{array}$ \\
\hline Beconase & & & \\
\hline Clarityne & & & \\
\hline Flixonase & & & \\
\hline Hismanal & & & \\
\hline Livostin & & & \\
\hline Nasacor & & & \\
\hline Polaratyne & & & \\
\hline Rhinocort & & & \\
\hline Rhinolast & & & \\
\hline Triludan & & & \\
\hline Triludan & & & \\
\hline Viarox & & & \\
\hline Zyrtec & & & \\
\hline OTHER: Please specify & & & \\
\hline
\end{tabular}

8. Do you aiways follow the exact instructions for taking rhinitis medication? Yes [ ] No [ ]

9. Please tick whichever of the following statements you agree with:

\begin{tabular}{|l|l|}
\hline I sometimes forget to take my medicine & \\
\hline I worry about side effects & \\
\hline I do not like the method of taking my medicine & \\
\hline I take what I know I need & \\
\hline I feel that taking medicine is admitting defeat & \\
\hline I cannot afford to pay for my medicine & \\
\hline I sometimes stop taking my medicine when I feel better & \\
\hline
\end{tabular}

10. Which do you prefer for your rhinitis? Nose spray [ ] Tablets [ ]

\section{What concerns do you have about your rhinitis?}

\begin{tabular}{|l|l|l|}
\hline & Yes & No \\
\hline That it may last life-long & & \\
\hline That you may not outgrow your rhinitis & & \\
\hline The effects of the medicines & & \\
\hline Passing rhinitis on to your children & & \\
\hline Feeling self-conscious about your rhinitis & & \\
\hline Having your social activities restricted & & \\
\hline
\end{tabular}

Thank you for completing this questionnaire 